Original article

\title{
Clinical characteristics and outcomes of psychotic depression in the Northern Finland Birth Cohort 1966
}

\author{
Miika Nietola $^{\mathrm{a}, *}$, Anni Heiskala ${ }^{\mathrm{b}}$, Tanja Nordström ${ }^{\mathrm{b}, \mathrm{c}}$, Jouko Miettunen ${ }^{\mathrm{b}, \mathrm{c}}$, Jyrki Korkeila ${ }^{\mathrm{e}}$, \\ Erika Jääskeläinen ${ }^{\text {b,c,d }}$ \\ a Psychiatric Department, University of Turku and the Hospital District of Southwest Finland, Finland \\ ${ }^{\mathrm{b}}$ Center for Life Course Health Research, University of Oulu, Oulu, Finland \\ ${ }^{\mathrm{c}}$ Medical Research Center Oulu, Oulu University Hospital and University of Oulu, Oulu, Finland \\ d Department of Psychiatry, Oulu University Hospital, Oulu, Finland \\ e Psychiatric Department, University of Turku and Satakunta Hospital District, Finland
}

\section{A R T I C L E I N F O}

\section{Article history:}

Received 15 February 2018

Received in revised form 4 May 2018

Accepted 8 May 2018

Available online 30 May 2018

Keywords:

Psychotic depression

Follow-up

Outcome

Psychosis

\begin{abstract}
A B S T R A C T
Background: Psychotic depression (PD) is heavily understudied despite high mortality and the severe course of illness. A majority of the studies conducted so far are also largely based on selected clinical samples. The aim of this study was to examine the clinical characteristics of PD in a representative prospective birth cohort sample.

Methods: The Northern Finland Birth Cohort 1966 is a well-known prospective population-based cohort including 12058 people followed since mid-pregnancy. We identified 55 individuals with PD, analysed their characteristics and compared them with schizophrenia (SZ), non-psychotic depression (NPD), psychotic bipolar disorder (PBD) and other psychoses (PNOS).

Results: The life-time prevalence of stable (no conversion to schizophrenia, bipolar disorder or schizoaffective disorder) PD was $0.5 \%$. PD subjects were older than SZ and PNOS subjects during the first psychotic episode and compared to SZ, more often female. PD required hospitalization and transition to disability pension more often than NPD, but less often than SZ. Comorbid alcohol abuse disorder (44\%) and personality disorder (40\%) were highly common in PD. PNOS had a similar occupational outcome than PD but hospitalization rate was lower in the PNOS group. PBD and PD had mostly comparable outcomes.

Conclusions: Our findings in a naturalistic cohort support the notion that the course of illness in PD is mostly similar to that of PBD, it is less severe than in schizophrenia, but worse than in non-psychotic depression. PD seems to have high psychiatric comorbidity.
\end{abstract}

(c) 2018 Elsevier Masson SAS. All rights reserved.

\section{Introduction}

Psychotic depression (PD) is currently classified as a severe form of Major Depression in ICD-10 [1], whereas in DSM-5, psychotic features are considered separate from severity of illness [2]. Meanwhile, there is a considerable number of factors supporting its role as a separate diagnostic entity with high mortality [3] and severe profile [4]. Considering the severity and impact of $\mathrm{PD}$, there has been insufficient research regarding it.

There have been some methodological differences between studies on the prevalence of PD, but it is likely to be relatively common with a lifetime prevalence of $0.35-1.0 \%$ and the prevalence

\footnotetext{
* Corresponding author at: Kunnallissairaalantie 20, Building 9, 20700, Turku, Finland.

E-mail address: mtniet@utu.fi (M. Nietola).
}

seems to increase in older age [5,6]. The gender distribution is comparable to that of NPD, with a higher proportion of females affected. Mean age of onset in early adulthood ( $<45$ years) in PD seems to be lower than in NPD, but higher than in NPD in later adulthood ( $>55$ years), which might be explained by PD being the first episode of bipolar disorder in younger samples. SZ is thought to have an earlier age of onset than PD altogether [7].

In light of previous studies, the overall outcome of PD seems to be worse than in NPD, but better than in SZ [7]. General medical comorbidity and psychiatric comorbidity have also been noted to be common in PD in some previous studies [8,9].

Many previous studies have some methodological issues to take into account. Concerning the outcome of PD, there are only a few first-episode samples with a long-term follow-up and they have mostly used inpatient samples from university clinics $[10,11]$. ÆSOP-10 in the UK followed PD patients in a well-designed firstepisode psychosis cohort for ten years. However, it lacked some 
representativeness due to loss to follow-up [12]. None of the firstepisode studies used non-psychotic depression as a comparison group. Other studies that have contributed to our knowledge of the outcome of PD have had either only inpatients, mixed samples with both first-episode and recurrent psychosis or only university clinic admissions [13-19].

Diagnostic instability of PD is considered high at least in young patient samples, reducing its nosological validity [20]. Psychotic symptoms are likely to be a risk factor for conversion from unipolar depression to bipolar disorder [21,22] and there is also a diagnostic shift to other diagnoses such as schizophrenia [23]. On the other hand, unipolar depression in later adulthood can be a prodromal phase for dementia or share a common etiology with it [24]. Heslin et al. [12] took diagnostic change into account in their study by analysing baseline and lifetime diagnoses separately but otherwise it has often been disregarded.

Little is known about the presentation of PD in natural settings, as many studies have included only inpatients. Especially studies on the risk factors and long-term outcome of PD in general are rare and desperately needed. Nationwide representative register databases, common in Scandinavia, provide a possibility to study PD. In Denmark, risk factors for illness [25], suicide [26], rehospitalizations [27] and diagnostic conversion [28] have been analysed using register data, but not other outcomes.

In this study, we aim to describe the clinical picture of PD in The Northern Finland Birth Cohort 1966 by the age of 48-49. We examine the clinical characteristics and outcomes of PD in comparison to NPD, SZ, PBD and PNOS in a representative prospective birth cohort sample during an up to 21-year followup. To our knowledge, this is the first prospective long-term birthcohort study observing PD, the first to widely use representative register data studying the long-term outcome of $\mathrm{PD}$, and the first study using non-psychotic depression, in addition to psychotic disorders, as a comparison group in a long-term follow-up of a first-episode PD sample.

\section{Material and methods}

\subsection{Case ascertainment}

The Northern Finland Birth Cohort 1966 study (NFBC 1966) is a prospective general population-based birth cohort study implemented in the provinces of Oulu and Lapland. There were 12058 live-born children followed since mid-pregnancy with expected birth in 1966 in this area of northern Finland that formed the birth cohort. We used nationwide registers for case identification and outcomes. Out of all NFBC 1966 members, we identified a total of 94 subjects who had been diagnosed with psychotic depression at some point in their life. We used the following diagnoses in different ICD-versions to identify PD: ICD-8: 2960, 2980; ICD-9: 2961E; ICD-10: F32.3, F33.3 (see Table 1 for diagnoses in comparison groups). All inpatient treatment diagnoses were gathered from the Care Register for Health Care (CRHC) [29] including all general and psychiatric hospitalizations from the beginning of the cohort study until 2013. We got outpatient treatment diagnoses from Finnish outpatient registers: the specialized outpatient care register was available from 1998 to 2013 and primary care from 2011 to 2013. The diagnoses information was supplemented with information from registers about the right for reimbursable medication for psychosis (1974-2005) and prescriptions for antipsychotics in 1997, and diagnosis leading to the right for a disability pension and sick leaves. Also, diagnoses based on validation of psychiatric diagnoses in 1997 [30] and a study performed for a subgroup of NFBC 1966 members at the age 43 years [31], were used as supplemental information.

We wanted to study the group that had a stable PD diagnosis and therefore moved those who had also been diagnosed with another specific psychotic disorder such as schizophrenia, bipolar disorder or schizoaffective disorder during the course of their psychiatric illness, to the respective diagnostic group. We used a hierarchical system, in which the life-time diagnosis for each subject was the one that had the highest position in the hierarchy. Starting from the top, the hierarchical order of diagnoses that defined the study group for each subject was: SZ, PBD, PD, PNOS, NPD. For example, subjects with a SZ diagnosis may have been diagnosed with something else, but their life-time diagnosis is interpreted to be SZ. NPD group subjects did not also have a diagnosis of any other study group because such a diagnosis would move them to the respective diagnostic group. We also checked that NPD group subjects did not have a lifetime occurrence of nonpsychotic bipolar disorder diagnosis. PD group subjects may have had short or undefined psychosis diagnoses (F23, F24, F28, F29) during their life-time and still stay in the PD group. An exception to the hierarchy was that we excluded 4 subjects who had both PD and delusional disorder (F22) diagnosis during their life-time. This is because our hierarchical diagnostic system situated these subjects in the PD group, while we did not interpret them to have stable PD since delusional disorder is a separate long-term psychotic illness. In the PD group, all psychiatric diagnoses of each subject were manually checked to make sure there were no diagnoses of SZ, PBD, non-psychotic bipolar disorder or delusional disorder. After this, there were 55 persons who formed the PD sample.

\subsection{Information on clinical characteristics and outcomes}

To evaluate the age of illness onset we identified the first psychosis and depression diagnosis by using the Care Register for Health Care, the Social Insurance Institution registers of reimbursable medicines and Finnish outpatient registers. Data on psychiatric comorbidity and hospitalization was obtained from the Care Register for Health Care and from outpatient registers from the beginning of the cohort in 1966 until the end of 2015. We analysed the proportion of workdays for the two-year period 2014-2015 based on data from the Finnish Center for Pensions (divided into: working under $25 \%, 25-50 \%, 50-75 \%$ and over $75 \%$ of working days). The information on disability pensions was gathered from the Finnish Center for Pensions (data until the end of 2015). The educational status data was from Statistics Finland registers until the end of 2015. Mortality rates were studied with the data from the Population Register Center until the end of 2015.

Table 1

Diagnostic categories based on ICD 8-10 used in the current study.

\begin{tabular}{|c|c|c|c|}
\hline & ICD-8 & ICD-9 & ICD-10 \\
\hline Psychotic depression (PD) & 2960, 2980 & $2961 \mathrm{E}$ & F32.3, F33.3 \\
\hline Non-psychotic Depression (NPD) & 3004,7902 & 3004 & F32.0-F32.2, F32.8-F33.2, F33.4-F33.9, F34.1, F38.10 \\
\hline Schizophrenia (SZ) & $295,2954,2957$ & $295,2954,2957$ & F20, F25 \\
\hline Psychotic Bipolar Disorder (PBD) & $2961-2969$ & 2962E, 2963E, 2964E, 2967 & F30.2, F31.2, F31.5 \\
\hline Other Psychoses (PNOS) & 297, 298 (except 2980), 299 & 297, 2988, 2989 & F22, F23, F24, F28, F29 \\
\hline
\end{tabular}


We analysed life-time hospitalization and comorbidity from birth until death, moving abroad or the end of follow-up in 31.12.2015. The follow-up time from illness onset (time of first occurrence of study group diagnosis in the register) until death, moving abroad or the end of follow-up in 31.12.2015 in different study groups were as follows: PD (Md: 7.4 years; IQR: 4.6-12.9 years); SZ(Md: 17.3 years; IQR: 11.623.6 years); PBD (Md: 11.0 years; IQR: $8.7-16.8$ years); PNOS (Md: 12.8 years; IQR: 6.7-21.0 years); NPD (Md: 8.3 years; IQR: 4.613.8 years) and the follow-up time after first any documented psychiatric diagnosis: PD (Md: 15.3 years; IQR: 8.9-21.6 years); SZ (Md: 22.5 years; IQR: 16.6-29.2 years); PBD (Md: 16.8 years; IQR: 11.0-26.2 years); PNOS (Md: 14.3 years; IQR: 8.6-24.1 years); NPD (Md: 9.9 years; IQR: 5.3-16.6 years).

\subsection{Statistical analyses}

Pearson's chi square test, Fisher's exact test and Mann-Whitney $U$ test were used to compare the PD group with SZ, NPD, PBD and PNOS groups. The findings were considered statistically significant when the two-tailed analysis resulted in a p value $<0.05$. Pearson's chi square test and Fisher's exact test were used to analyse the differences in gender, comorbidity, mortality, disability pension rate, proportion of working days, educational level and the amount of subjects with at least one life-time occurrence of hospitalization. Mann-Whitney $U$ test was used to analyse differences in median (Md) onset-ages, median cumulative hospitalization days, median amount of hospitalizations and the relative proportion of hospitalization days from illness onset to the end of follow-up or death. For the survival curves, we applied the log rank test. When analysing the differences in hospitalization and comorbidity, we did not adjust for duration of illness, since we used data of life-time diagnoses and hospitalization in all groups. However, the variable "relative proportion of hospitalization days from illness onset to the end of follow-up or death" took the time of illness onset into account since it included the time of first group diagnosis as a starting point. In the survival curve analysis of readmissions, we used first life-time occurrence of hospitalization due to any psychiatric illness as an index episode. The adjustment for duration of illness was also not done when comparing occupational status and mortality. R version 3.3.2 (http://www. R-project.org) was used for statistical analyses.

\section{Results}

\subsection{Sample}

The sample consisted of 55 PD subjects and the following comparison groups: NPD $(n=618), S Z(n=181), \operatorname{PBD}(n=29)$ and PNOS $(n=134)$. There was a female majority in the PD group and a significant difference compared to SZ $(\mathrm{p}<0.05)$ but no other statistically significant differences in gender distribution between groups (Table 2). With 55 PD subjects, the lifetime prevalence of stable PD up to the end of 2013 in the birth cohort sample was found to be $0.5 \%$.

\subsection{Clinical course and hospitalization}

SZ subjects were significantly younger $(27.9 \mathrm{y})(\mathrm{p}<0.001)$ than PD subjects (38.4y) during the first psychotic episode (Table 2). The age of PD subjects during first depression diagnosis (37.5y) was significantly lower than for NPD subjects $(40.7 \mathrm{y})(\mathrm{p}<0.05)$ (Table 2$)$.

Mortality in PD $(11 \%, \mathrm{n}=6)$ was higher than in NPD $(7 \%, \mathrm{n}=41)$ and PBD $(7 \%, \mathrm{n}=2)$ but lower than in SZ $(14 \%, \mathrm{n}=26)$ and PNOS $(15 \%, n=20)$. However, there were no statistically significant differences between groups (Table 2).

The median number of cumulative hospitalization days for any psychiatric indication was 84 in the PD group which was significantly lower $(\mathrm{p}<0.001)$ than in SZ $(254)$ and significantly higher than in NPD $(0)(\mathrm{p}<0.001)$ and PNOS (39 days) $(\mathrm{p}<0.05)$ (Table 4). PD subjects had significantly more hospitalizations (5) than NPD $(0)(\mathrm{p}<0.001)$ and PNOS $(2)(\mathrm{p}<0.01)$ subjects but less than SZ subjects $(8)(p<0.01)$ (Table 4$)$. The relative proportion of hospitalization days from illness onset to the end of follow-up or death in PD (2.07) was significantly higher than in NPD (0) $(\mathrm{p}<0.001)$ or PNOS $(0.86)(\mathrm{p}<0.01)$ but significantly lower than in SZ (5.62) $(\mathrm{p}<0.01)$ (Table 4$)$.

We also compared the number of subjects with at least one life-time hospitalization episode due to psychiatric illness in

Table 2

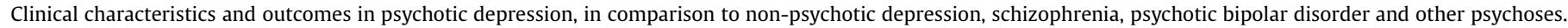
( ${ }^{*}=$ Fisher's exact test; $\mathrm{md}=$ Median; IQR = Interquartile range).

\begin{tabular}{|c|c|c|c|c|c|c|c|c|c|c|c|c|c|c|}
\hline \multirow[t]{2}{*}{ Variable } & \multicolumn{2}{|c|}{$\begin{array}{l}\text { Psychotic } \\
\text { Depression (PD) } \\
(n=55)\end{array}$} & \multicolumn{2}{|c|}{$\begin{array}{l}\text { Non-psychotic } \\
\text { Depression } \\
(\mathrm{NPD})(\mathrm{n}=618)\end{array}$} & \multicolumn{2}{|c|}{$\begin{array}{l}\text { Schizophrenia } \\
(\mathrm{SZ})(\mathrm{n}=181)\end{array}$} & \multicolumn{2}{|c|}{$\begin{array}{l}\text { Psychotic } \\
\text { Bipolar Disorder } \\
(\mathrm{PBD})(\mathrm{n}=29)\end{array}$} & \multicolumn{2}{|c|}{$\begin{array}{l}\text { Other Psychoses } \\
\text { (PNOS) }(n=134)\end{array}$} & \multicolumn{4}{|c|}{ Statistical significance, p-value } \\
\hline & $\mathrm{n}$ & $\%$ & $\mathrm{n}$ & $\%$ & $\mathrm{n}$ & $\%$ & $\mathrm{n}$ & $\%$ & $\mathrm{n}$ & $\%$ & $\begin{array}{l}\text { PD vs. } \\
\text { NPD }\end{array}$ & $\begin{array}{l}\text { PD vs. } \\
\text { SZ }\end{array}$ & $\begin{array}{l}\text { PD vs. } \\
\text { PBD }\end{array}$ & $\begin{array}{l}\text { PD vs. } \\
\text { PNOS }\end{array}$ \\
\hline Gender, n/\% & & & & & & & & & & & 0.66 & 0.030 & 0.84 & 0.18 \\
\hline Male & 24 & 43.6 & 289 & 46.8 & 109 & 60.2 & 12 & 41.4 & 73 & 54.5 & & & & \\
\hline Female & 31 & 56.4 & 329 & 53.2 & 72 & 39.8 & 17 & 58.6 & 61 & 45.5 & & & & \\
\hline Educational level, n/\% & & & & & & & & & & & 0.27 & 0.09 & 0.59 & 0.56 \\
\hline Low & 13 & 23.6 & 95 & 15.4 & 51 & 28.2 & 5 & 17.2 & 32 & 23.9 & & & & \\
\hline Middle & 24 & 43.6 & 307 & 49.7 & 96 & 53 & 16 & 55.2 & 68 & 50.7 & & & & \\
\hline High & 18 & 32.7 & 216 & 35 & 34 & 18.8 & 8 & 27.6 & 34 & 25.4 & & & & \\
\hline $\begin{array}{l}\text { Age of illness onset, psychosis, } \\
\text { md/IQR }\end{array}$ & 38.4 & $35.2-44.0$ & - & - & 27.9 & $21.7-33.3$ & 37.2 & $30.6-40.6$ & 34.2 & $27.2-41.9$ & - & $<0.001$ & 0.08 & $<0.001$ \\
\hline $\begin{array}{l}\text { Age of illness onset, } \\
\text { depression, md/IQR }\end{array}$ & 37.5 & $33.5-41.5$ & 40.7 & $34.6-44.5$ & & & & & & & 0.011 & & & \\
\hline \multicolumn{15}{|l|}{ Psychiatric comorbidity, n/\% } \\
\hline Any substance use disorder & 25 & 45.5 & 155 & 25.1 & 40 & 22.1 & 8 & 27.6 & 37 & 27.6 & 0.001 & $<0.001$ & 0.11 & 0.018 \\
\hline Alcohol use disorder & 24 & 43.6 & 151 & 24.4 & 35 & 19.3 & 8 & 27.6 & 34 & 25.4 & 0.002 & $<0.001$ & 0.15 & 0.013 \\
\hline Anxiety disorder & 20 & 36.4 & 217 & 35.1 & 55 & 30.4 & 12 & 41.4 & 46 & 34.3 & 0.85 & 0.40 & 0.65 & 0.79 \\
\hline Personality disorder & 22 & 40.0 & 112 & 18.1 & 65 & 35.9 & 9 & 31.0 & 43 & 32.1 & $<0.001$ & 0.58 & 0.42 & 0.30 \\
\hline Mortality, n/\% & 6 & 10.9 & 41 & 6.6 & 26 & 14.4 & 2 & 6,9 & 20 & 14.9 & $0.26^{*}$ & 0.51 & $0.71^{*}$ & 0.47 \\
\hline Disability pension, $\mathbf{n} / \%$ & & & & & & & & & & & $<0.001$ & $<0.001$ & 0.25 & 0.83 \\
\hline yes & 23 & 46.9 & 114 & 19.8 & 125 & 81.2 & 9 & 33.3 & 51 & 45.1 & & & & \\
\hline no & 26 & 53.1 & 462 & 80.2 & 29 & 18.8 & 18 & 66.7 & 62 & 54.9 & & & & \\
\hline
\end{tabular}


Table 3

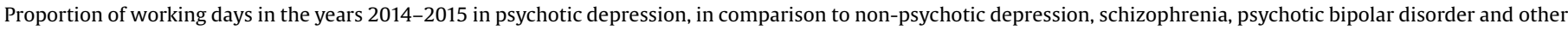
psychoses. Deceased subjects are excluded. (Fisher's exact test).

\begin{tabular}{|c|c|c|c|c|c|c|c|c|c|c|c|c|c|c|}
\hline \multirow[t]{2}{*}{ Proportion of working days in 2014-2015 } & \multicolumn{2}{|c|}{$\begin{array}{l}\text { Psychotic } \\
\text { Depression } \\
(\mathrm{PD}) \\
(\mathrm{n}=49)\end{array}$} & \multicolumn{2}{|c|}{$\begin{array}{l}\text { Non- } \\
\text { psychotic } \\
\text { Depression } \\
(\mathrm{NPD}) \\
(\mathrm{n}=575)\end{array}$} & \multicolumn{2}{|c|}{$\begin{array}{l}\text { Schizophrenia } \\
(\mathrm{SZ})(\mathrm{n}=154)\end{array}$} & \multicolumn{2}{|c|}{$\begin{array}{l}\text { Psychotic } \\
\text { Bipolar } \\
\text { Disorder } \\
(\mathrm{PBD}) \\
(\mathrm{n}=27)\end{array}$} & \multicolumn{2}{|c|}{$\begin{array}{l}\text { Other } \\
\text { Psychoses } \\
\text { (PNOS) } \\
(\mathrm{n}=112)\end{array}$} & \multicolumn{4}{|c|}{ Statistical significance, p-value } \\
\hline & $\mathrm{n}$ & $\%$ & $\mathrm{n}$ & $\%$ & $\mathrm{n}$ & $\%$ & $\mathrm{n}$ & $\%$ & $\mathrm{n}$ & $\%$ & PD vs. NPD & PD vs. SZ & PD vs. PBD & PD vs. PNOS \\
\hline & & & & & & & & & & & $0.006^{*}$ & $<0.001^{*}$ & $0.93^{*}$ & $0.76^{*}$ \\
\hline$<25 \%$ & 33 & 67.3 & 235 & 40.9 & 139 & 90.3 & 17 & 63.0 & 74 & 66.1 & & & & \\
\hline $25-49.9 \%$ & 2 & 4.1 & 38 & 6.6 & 2 & 1.3 & 1 & 3.7 & 10 & 8.9 & & & & \\
\hline $50-74.9 \%$ & 2 & 4.1 & 47 & 8.2 & 1 & 0.6 & 2 & 7.4 & 4 & 3.6 & & & & \\
\hline$\geq 75 \%$ & 12 & 24.5 & 255 & 44.3 & 12 & 7.8 & 7 & 25.9 & 24 & 21.4 & & & & \\
\hline
\end{tabular}

Table 4

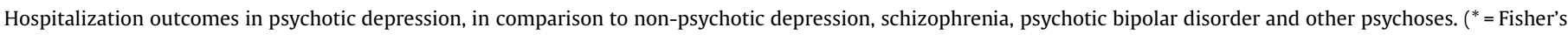
exact test; $\mathrm{md}=$ Median; $\mathrm{IQR}=$ Interquartile range).

\begin{tabular}{|c|c|c|c|c|c|c|c|c|c|c|c|c|c|c|}
\hline \multirow[t]{2}{*}{ Variable } & \multicolumn{2}{|c|}{$\begin{array}{l}\text { Psychotic } \\
\text { Depression (PD) } \\
(n=55)\end{array}$} & \multicolumn{2}{|c|}{$\begin{array}{l}\text { Non- } \\
\text { psychotic } \\
\text { Depression } \\
(\mathrm{NPD}) \\
(\mathrm{n}=618)\end{array}$} & \multicolumn{2}{|c|}{$\begin{array}{l}\text { Schizophrenia } \\
(\mathrm{SZ})(\mathrm{n}=181)\end{array}$} & \multicolumn{2}{|c|}{$\begin{array}{l}\text { Psychotic } \\
\text { Bipolar Disorder } \\
(\mathrm{PBD})(\mathrm{n}=29)\end{array}$} & \multicolumn{2}{|c|}{$\begin{array}{l}\text { Other Psychoses } \\
\text { (PNOS) }(n=134)\end{array}$} & \multicolumn{4}{|c|}{ Statistical significance, $\mathrm{p}$-value } \\
\hline & $\mathrm{n}$ & $\%$ & $\mathrm{n}$ & $\%$ & $\mathrm{n}$ & $\%$ & $\mathrm{n}$ & $\%$ & $\mathrm{n}$ & $\%$ & $\begin{array}{l}\text { PD vs. } \\
\text { NPD }\end{array}$ & $\begin{array}{l}\text { PD vs. } \\
\text { SZ }\end{array}$ & $\begin{array}{l}\text { PD vs. } \\
\text { PBD }\end{array}$ & $\begin{array}{l}\text { PD vs. } \\
\text { PNOS }\end{array}$ \\
\hline $\begin{array}{l}\text { Psychiatric hospitalization periods, } \\
\text { cumulative amount, Md/IQR }\end{array}$ & 5 & $2-9$ & 0 & $0-2$ & 8 & $3-16$ & 4 & $1-7$ & 2 & $1-5$ & $<0.001$ & 0.002 & 0.55 & 0.003 \\
\hline $\begin{array}{l}\text { Psychiatric hospitalization days, } \\
\text { cumulative amount, Md/IQR }\end{array}$ & 84 & $24-160$ & 0 & $0-12$ & 254 & $102-633$ & 76 & $39-183$ & 39 & $10-90$ & $<0.001$ & $<0.001$ & 0.83 & 0.012 \\
\hline $\begin{array}{l}\text { Proportion of psychiatric hospitalization } \\
\text { days from illness onset until death or } \\
\text { end of follow-up (\%) }\end{array}$ & 2.07 & $0.95-6.36$ & 0 & $0-0.41$ & 5.62 & $2.22-10.59$ & 1.75 & $0.45-6.28$ & 0.86 & $0.22-3.06$ & $<0.001$ & 0.004 & 0.46 & 0.002 \\
\hline At least one lifetime hospitalization, $n / \%$ & 53 & 96.4 & 276 & 44.7 & 172 & 95.0 & 24 & 82.8 & 117 & 87.3 & $<0.001$ & $>0.99^{*}$ & $0.045^{*}$ & 0.06 \\
\hline $\begin{array}{l}\text { Psychiatric hospitalization days, } \\
\text { cumulative amount (for those having } \\
\text { at least one life-time hospitalization) }\end{array}$ & 84 & $30-160$ & 15 & $5-45$ & 268 & $113-663$ & 83 & $56-225$ & 46 & 19-109 & $<0.001$ & $<0.001$ & 0.15 & 0.08 \\
\hline
\end{tabular}

different groups. Almost all PD subjects had been hospitalized (96\%), which was comparable to the SZ hospitalization rate (95\%) and significantly more common than in the NPD group $(45 \%)(\mathrm{p}<0.001)$ and in the PBD group $(83 \%)(\mathrm{p}<0.05)$ (Table 4). Among only those subjects with at least one lifetime psychiatric hospitalization, PD subjects still had many more hospital days than NPD subjects ( 84 vs. 15$)(\mathrm{p}<0.001)$ and less than SZ subjects $(268)(\mathrm{p}<0.001)$ (Table 4$)$.

We also carried out a survival curve analysis of readmissions in diagnostic groups after the first life-time occurrence of hospitalization due to any psychiatric illness with a 20-year follow-up (Figs. 1-4). PD subjects had a statistically significant shorter time to readmission than NPD subjects $(\mathrm{p}<0.01)$ and longer than SZ subjects $(\mathrm{p}<0.05)$.

\subsection{Comorbidity}

The prevalence of substance abuse disorders was remarkably high in PD subjects: $46 \%$ had at least one documented occurrence of substance abuse disorder and $44 \%$ had a documented occurrence of alcohol abuse disorder, which were significantly more than in NPD (25\% and 24\%) ( $p<0.01$ both), SZ (22\% and 19\%) ( $<<0.001$ both) and PNOS $(28 \%$ and $25 \%)(\mathrm{p}<0.05)$ (Table 2$)$. Personality disorders were also more prevalent in the PD group (40\%) than in the other groups (NPD 18\%; SZ 36\%; PBD 31\%; PNOS 32\%) but the difference was statistically significant only between PD and NPD $(\mathrm{p}<0.001)$ (Table 2$)$.

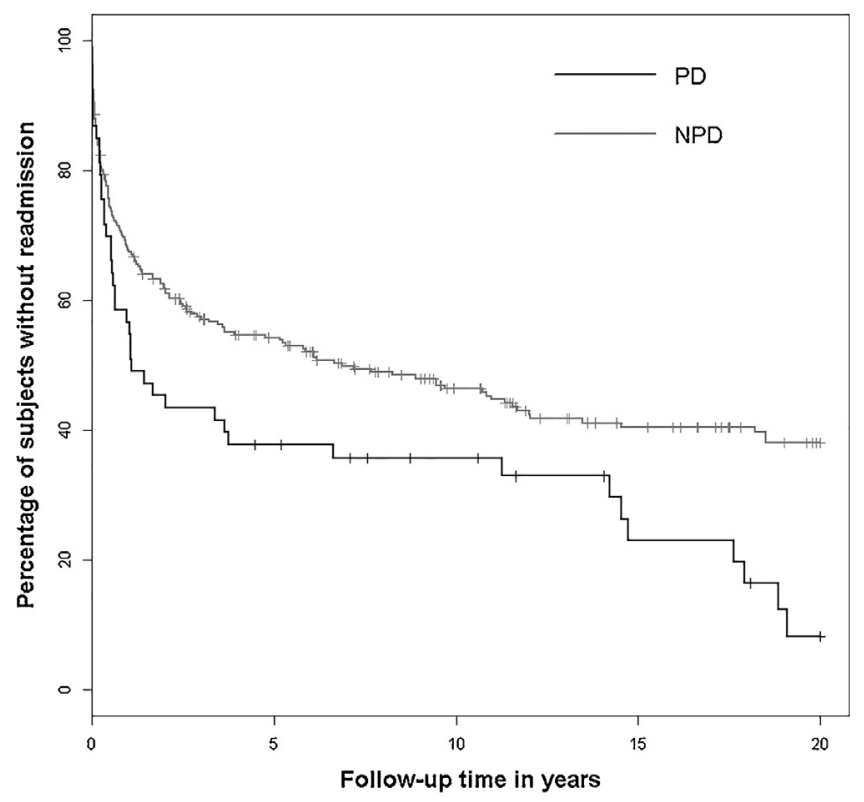

Fig. 1. Psychotic Depression (PD) vs. Non-psychotic Depression (NPD) $(p<0.01)$.

\subsection{Educational and occupational status}

The differences in educational level between PD and other groups did not quite reach statistical significance (Table 2). 


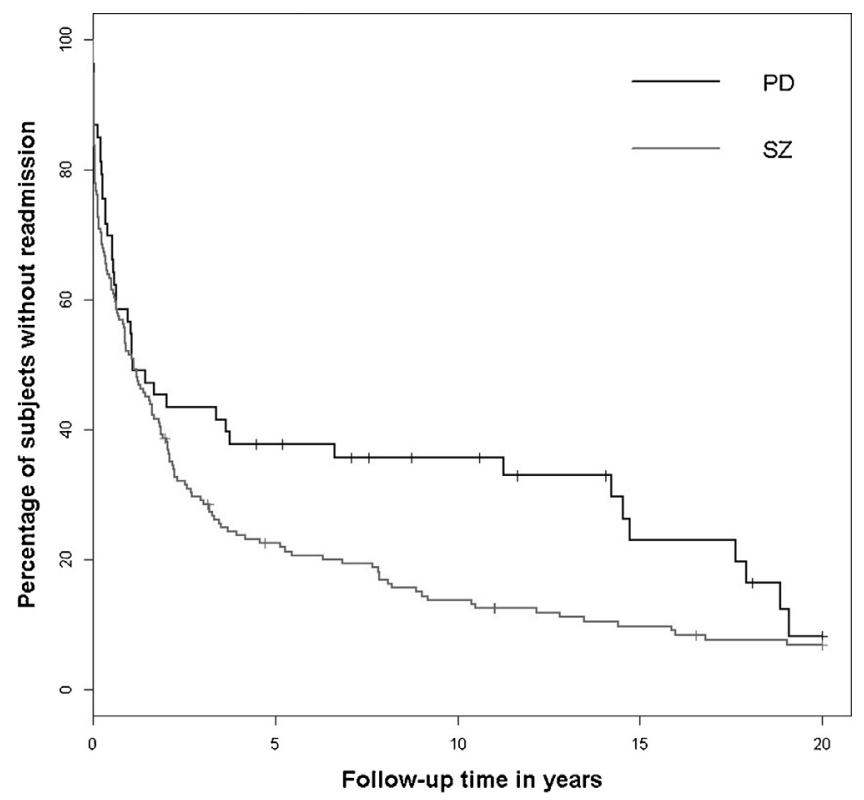

Fig 2. Psychotic Depression (PD) vs. Schizophrenia (SZ) $(\mathrm{p}<0.05)$.

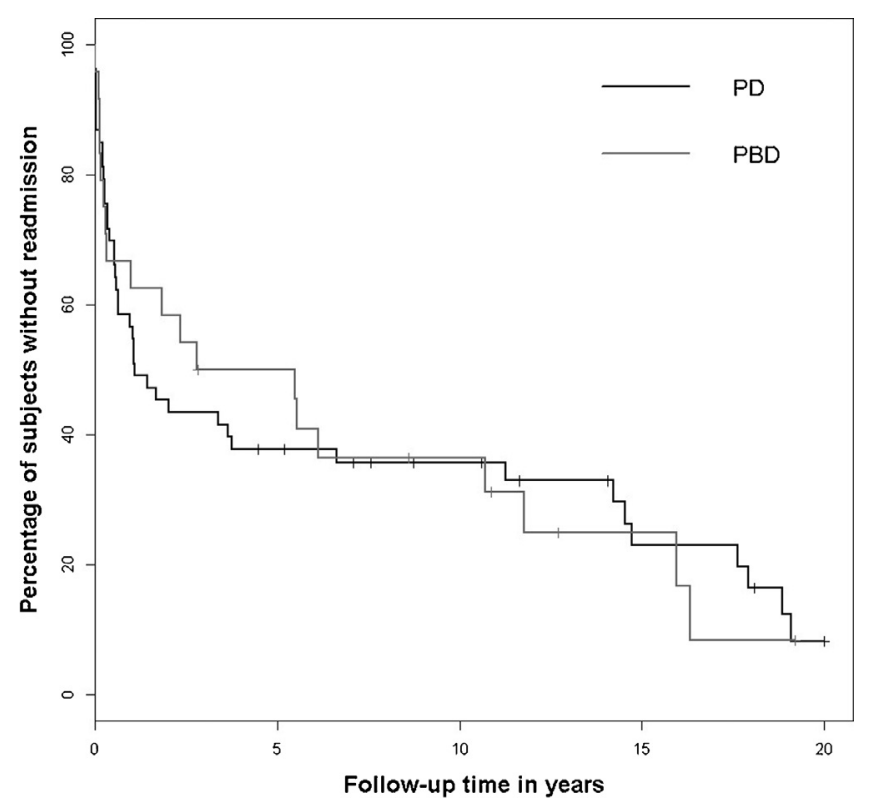

Fig. 3. Psychotic Depression (PD) vs. Psychotic Bipolar Disorder (PBD).

However, we identified a distinctive occupational profile in PD subjects who were significantly more often $(\mathrm{p}<0.001)$ on disability pension (47\%) than NPD subjects (20\%) but less often $(\mathrm{p}<0.001)$ than those with SZ $(81 \%)$ (Table 2$)$. To study the occupational outcome more closely, we analysed the proportion of workdays for the two-year period 2014-2015 (divided into under $25 \%, 25-50 \%, 50-75 \%$ and over $75 \%$ ) (Table 3 ). We found that PD subjects were more actively involved in work than SZ subjects $(\mathrm{p}<0.001)$, but less than NPD subjects $(\mathrm{p}<0.01)$ (Table 3$)$.

\section{Discussion}

Our study shows that in the long term, PD has more malign clinical and occupational outcomes and a more severe clinical profile than NPD in a general population sample. Meanwhile, the

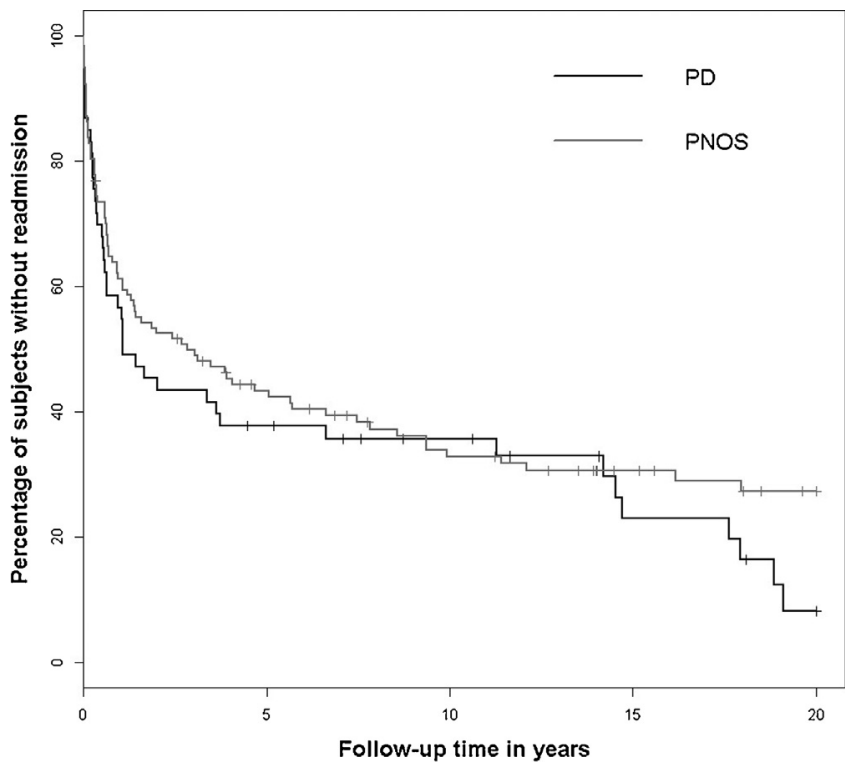

Fig 4. Psychotic Depression (PD) vs. Other Psychoses (PNOS).

outcomes and the clinical profile in SZ are worse than in PD. Results comparing PD to PBD and PNOS were not so straightforward. PNOS had a younger onset-age and better hospitalization outcomes, while PBD was mostly comparable to PD.

Prevalence of PD in the Northern Finland Birth Cohort 1966 was $0.5 \%$ by the age of $48-49$, the scale of which was as expected, but it is still rather high when considering our exclusion of unstable cases, the age of the sample and higher incidence of PD in older age. The gender distribution with more females affected was in line with a recent meta-analysis, although the proportion of females was slightly lower (56\% vs. 65\%). Our findings concerning onsetage in PD had no incongruity with previous studies either [7]. However, the earlier onset-age of PD compared to NPD is not reliable because our outpatient data began in 1998, which means that especially NPD cases treated only in outpatient care before 1998 were missed.

Our finding of higher mortality in PD than NPD, though not statistically significant, is comparable to previous research [3]. When analysing all affective psychoses as a group, there have also been contradictory results [32].

To our knowledge, there are no previous studies comparing the amount of psychiatric hospitalizations in a prospective long-term follow-up between PD and NPD. In some previous studies, PD subjects have been hospitalized more frequently than NPD subjects $[27,33,34]$, but there are also studies with no differences between PD and NPD groups [35]. In a recent systematic review, there was a trend towards more hospitalization in PD but no major difference between groups [7]. Affecting this finding was a study by Buoli et al. [36] who found PD subjects had fewer hospitalizations than NPD subjects, while simultaneously the current hospitalization had a longer duration in the PD group. SZ patients have most often been found to have more hospitalizations than PD patients even though results have been partly contradictory $[12,34,37]$. In our study, we found that PD subjects were significantly more often hospitalized and required more hospital days than NPD subjects, but significantly less than SZ subjects. These differences appeared both in life-time occurrences of hospitalizations and separately in the post-illness-onset period measured by the variable "relative proportion of hospitalization days from illness onset to the end of follow-up or death". Time to readmission in the PD group was shorter than in the NPD group but 
longer than in the SZ group. There were more subjects in the PBD group who had no life-time occurrences of hospitalizations than in the PD group, but otherwise these groups had a similar hospitalization outcome. PD subjects had more hospitalizations than PNOS subjects in our study.

Previous studies comparing the occupational outcome in PD and NPD have not been explicit. In some studies employment rates in PD have been found to be high [11] and not to differ from NPD [34,38]. In sharp contrast, Rush et al. [39] found 90\% of PD subjects were unemployed, but also the unemployment rate of NPD subjects was exceptionally high (81\%) in the study, which is likely not representative in an occupational perspective. Coryell and Tsuang [13] identified a similar occupational outcome in PD and NPD in a 40-year follow-up when psychotic symptoms were mood-congruent, but a worse outcome for PD when there were mood-incongruent symptoms. SZ subjects have had worse occupational outcomes in previous studies than PD subjects [34]. In our study, disability pension was significantly more common and the amount of annual workdays lower among subjects with PD than NPD. The opposite was the case in the SZ group, which had a higher disability pension rate and lower number of annual workdays than the PD group. The disability pension rate or the number of annual workdays of PD was not significantly different from the PBD or PNOS groups.

Results of high prevalence of comorbid substance and especially alcohol abuse and personality disorder observed in the PD group in our study are similar to those in some previous studies [8,9] but low illicit drug abuse in PD has also been reported previously [37]. Surprisingly, comorbid substance abuse was more common in PD than in other diagnostic groups. It is also possible to speculate that substance abuse has a role in high physical comorbidity [8] and mortality [3] as well as in the clinical and occupational outcome observed in PD.

Depression has been found to be common in different stages of SZ and it may interplay with SZ in its progression, which has raised questions about the validity of PD diagnosis [40]. Our findings of older onset-age, female majority and better outcome in PD compared to SZ situate PD on a very different part of the psychosis spectrum. These findings are also in concordance with a recent study that found male sex, younger age and psychotic symptoms to be predictive of progression from unipolar depression to schizophrenia [41]. It is also interesting that depression in schizophrenia and first-episode psychosis is associated with poorer outcomes [42-45], while PD has a more benign clinical picture than SZ. In other words, it is puzzling why PD as a psychotic illness with a better outcome is characterized by the prognostic marker of poor psychosis outcome. More research on PD is urgently called for to better understand these phenomena and the connections between depression and psychosis.

\subsection{Strengths and limitations}

Our naturalistic study design, with a real-world non-selected sample, is the first of its kind in PD studies. We used reliable [29] register data from different sources. Follow-up time was comparatively long and we had a chance to compare PD to several other psychoses and NPD in the same study population. In addition, we were able to analyse many different outcome dimensions and variables in the same sample and therefore gained a comprehensive understanding of the outcome.

A significant limitation in our study was the beginning of outpatient register data as late as 1998 when the cohort population was over 30 years old. We cannot rule out that some subjects may have been previously diagnosed with PD during prior outpatient care. Since most (96.4\%) PD subjects had been hospitalized and the median onset-age was high ( 38 years), this is not a major concern. In addition, the number of psychiatric hospital beds in Finland decreased rapidly in the 1980s and 1990s when at the same time the amount of outpatient care grew significantly [46], therefore the scenario of PD subjects being merely in outpatient care would have been more likely after 1998 . However, the prevalence observed for NPD is probably underestimated since many subjects most likely had been diagnosed with NPD before 1998 and treated in outpatient care. Many PD subjects might have also been diagnosed with non-psychotic depression before 1998. Altogether, the observed age of first depression diagnosis is likely biased upwards in all diagnostic groups studied.

The older onset-age of NPD compared to PD is not reliable. We were not able to get information about the early-onset outpatient NPD cases, and this may affect the comparisons made between the NPD and PD groups. However, these potential early cases who were not included in our data were likely to have a good prognosis since they did not have any life-time occurrences of hospitalizations or outpatient care with NPD diagnosis after 1998. Therefore, including these cases in our study would have presumably only magnified the difference observed in outcome between NPD and PD. Thus, our conclusion that PD has a more severe course of illness than NPD is reliable.

In addition, the small sample size of PBD subjects makes it hard to draw many conclusions. Possibly due to this, many differences between PD and PBD remained non-significant. There are still some factors, such as the group of subjects with no life-time occurrences of hospitalizations, that indicate a more benign course for PBD.

One limitation in our study is the use of changing diagnostic classifications from ICD-8 to ICD-10. PD is not as clearly defined in ICD-8 and ICD-9 than in ICD-10, which came into use in 1996 in Finland. The chosen PD diagnoses in ICD-8 $(2960 ; 2980)$ and ICD-9 (2961E) are non-organic psychotic states with cooccurring significant depressive symptoms. The validity of our method is increased by the hierarchical system of life-time diagnosis. Those patients diagnosed with PD during ICD-8 and ICD-9 were excluded from the PD group if they, later in life, were diagnosed with schizophrenia, schizoaffective disorder or bipolar disorder.

When comparing mortality and occupational status, we did not adjust for duration of illness. The birth cohort study design allowed us to observe the naturalistic trajectories of different study groups, and we compared the mortality rate and occupational status at the same age in all participants.

Our study design makes it possible that some cases might have gone undiagnosed due to no contact with health-care providers. We believe this risk with PD is small in a mostly publicly funded Finnish healthcare system. Misdiagnosis has been found to be high in PD [47] and this is a limitation that we are not able to rule out.

\section{Conclusions}

PD sample in the NFBC 1966 cohort showed a distinct clinical profile with high comorbidity and a less severe profile than SZ but more severe than NPD. PD and PBD group outcomes were largely comparable, though PD subjects more often had at least one lifetime occurrence of hospitalization. Especially high rates of substance abuse and personality disorder in PD in our naturalistic sample were surprising. In addition, the high hospitalization rates and mortality, as well as low functional status displayed in employment outcomes, highlight the severity of PD. These are important notions that clinicians should take into account when treating subjects with PD. Given the current lack of studies, PD needs also more scientific attention. 


\section{Role of the funding source}

This work was supported by grants from the Academy of Finland (grant numbers 278286, 268336), the Sigrid Jusélius Foundation, the Brain \& Behavior Research Foundation. The funders had no role in the study design, data collection, data analysis, interpreting the results or the decision to publish the article.

\section{Declarations of interest}

None.

\section{References}

[1] WHO. International Classification of Diseases and Related Health Problems. Geneva: World Health Organization; 1992 10th revision.

[2] American Psychiatric Association (APA). Diagnostic and Statistical Manual of Mental Disorders. 5th ed.: dsm-5 Arlington, VA: American Psychiatric Publishing; 2013.

[3] Vythilingam M, Chen J, Bremner JD, Mazure CM, Maciejewski PK, Nelson JC. Psychotic depression and mortality. Am J Psychiatry 2003;160(March (3)):574-6.

[4] Keller J, Schatzberg AF, Maj M. Current issues in the classification of psychotic major depression. Schizophr Bull 2007;33:877-85.

[5] Perälä J, Suvisaari J, Saarni SI, Kuoppasalmi K, Isometsä E, Pirkola S, et al. Lifetime prevalence of psychotic and bipolar I disorders in a general population. Arch Gen Psychiatry 2007;64:19-28.

[6] Kivelä SL, Pahkala K. Delusional depression in the elderly: a community study. Z Gerontol 1989:22(September-October (5)):236-41.

[7] Jääskeläinen E, Juola T, Korpela H, Lehtiniemi H, Nietola M, Korkeila J, et al. Epidemiology of psychotic depression - systematic review and meta-analysis. Psychol Med 2017:12(September):1-14.

[8] Tohen M, Khalsa HK, Salvatore P, Vieta E, Ravichandran C, Baldessarini RJ. Twoyear outcomes in first-episode psychotic depression: the McLean-Harvard First-Episode Project. J Affect Disord 2012;136(January (1-2)):1-8.

[9] Gaudiano BA, Weinstock LM, Epstein-Lubow G, Uebelacker LA, Miller IW. Clinical characteristics and medication use patterns among hospitalized patients admitted with psychotic vs nonpsychotic major depressive disorder Ann Clin Psychiatry 2016;28(February (1)):56-63.

[10] Jarbin H, Ott Y, Von Knorring AL. Adult outcome of social function in adolescent-onset schizophrenia and affective psychosis. J Am Acad Child Adolesc Psychiatry 2003;42(February (2)):176-83.

[11] Opjordsmoen S. Unipolar delusional depression: Outcome in reactive versus endogenous types. Psychopathology 1991;24(5):260-9.

[12] Heslin M, Lappin JM, Donoghue K, Lomas B, Reininghaus U, Onyejiaka A, et al. Ten-year outcomes in first episode psychotic major depression patients compared with schizophrenia and bipolar patients. Schizophr Res 2016;176 (October (2-3)):417-22.

[13] Coryell W, Tsuang MT. Major depression with mood-congruent or moodincongruent psychotic features: outcome after 40 years. Am J Psychiatry 1985;142(April (4)):479-82.

[14] Goldberg JF, Harrow M. Consistency of remission and outcome in bipolar and unipolar mood disorders: a 10-year prospective follow-up. J Affect Disord 2004;81 (August (2)):123-31.

[15] Coryell W, Leon A, Winokur G, Endicott J, Keller M, Akiskal H, et al. Importance of psychotic features to long-term course in major depressive disorder. Am Psychiatry 1996;153(April (4)):483-9.

[16] Angst J. The course of affective disorders. Psychopathology 1986;19(Suppl. 2):47-52.

[17] Brockington IF, Helzer JE, Hillier VF, Francis AF. Definitions of depression: concordance and prediction of outcome. Am J Psychiatry 1982;139(August (8)):1022-7.

[18] Copeland JR. Psychotic and neurotic depression: discriminant function analysis and five-year outcome. Psychol Med 1983:13(May (2)):373-83.

[19] Maj M, Pirozzi R, Di Caprio EL. Major depression with mood-congruent psychotic features: a distinct diagnostic entity or a more severe subtype of depression? Acta Psychiatr Scand 1990;82(December (6)):439-44.

[20] Heslin M, Lomas B, Lappin JM, Donoghue K, Reininghaus U, Onyejiaka A, et al. Diagnostic change 10 years after a first episode of psychosis. Psychol Med 2015;45(October (13)):2757-69.

[21] Kessing LV, Willer I, Andersen PK, Bukh JD. Rate and predictors of conversion from unipolar to bipolar disorder: a systematic review and meta-analysis Bipolar Disord 2017;19(August (5)):324-35.

[22] Ratheesh A, Davey C, Hetrick S, Alvarez-Jimenez M, Voutier C, Bechdolf A, et al. A systematic review and meta-analysis of prospective transition from major depression to bipolar disorder. Acta Psychiatr Scand 2017;135(April(4)):273-84.

[23] Bromet EJ, Kotov R, Fochtmann LJ, Carlson GA, Tanenberg-Karant M, Ruggero C, et al. Diagnostic shifts during the decade following first admission for psychosis. Am J Psychiatry 2011;168(November (11)):1186-94.

[24] Singh-Manoux A, Dugravot A, Fournier A, Abell J, Ebmeier K, Kivimäki M, et al Trajectories of depressive symptoms before diagnosis of dementia: a 28-Yea follow-up study. JAMA Psychiatry 2017;74(July (7)):712-8.
[25] Ostergaard SD, Waltoft BL, Mortensen PB, Mors O. Environmental and familial risk factors for psychotic and non-psychotic severe depression. J Affect Disord 2013;147(May (1-3)):232-40.

[26] Leadholm AK, Rothschild AJ, Nielsen J, Bech P. Ostergaard SD. Risk factors for suicide among 34,671 patients with psychotic and non-psychotic severe depression. J Affect Disord 2014;156(March):119-25.

[27] Kessing LV. Subtypes of depressive episodes according to ICD-10: prediction of risk of relapse and suicide. Psychopathology 2003:36(November-December (6)):285-91.

[28] Østergaard SD, Straszek S, Petrides G, Skadhede S, Jensen SO, Munk-Jørgensen P. et al. Risk factors for conversion from unipolar psychotic depression to bipolar disorder. Bipolar Disord 2014;16(March (2)):180-9.

[29] Keskimäki I, Aro S. Accuracy of data on diagnoses, procedures and accidents in the Finnish Hospital Discharge Register. Int J Health Sci 1991;2:15-21.

[30] Moilanen K, Veijola J, Läksy K, Mäkikyrö T, Miettunen J, Kantojärvi L, et al. Reasons for the diagnostic discordance between clinicians and researchers in schizophrenia in the Northern Finland 1966 Birth Cohort. Soc Psychiatry Psychiatr Epidemiol 2003:38(6):305-10.

[31] Nykänen S, Puska V, Tolonen JP, Salo H, Isohanni M, Koponen H, et al. Use of psychiatric medications in schizophrenia and other psychoses in a general population sample. Psychiatry Res 2016;30(January (235)):160-8.

[32] Suvisaari J, Partti K, Perälä J, Viertio S, Saarni SE, Lönnqvist J, et al. Mortality and its determinants in people with psychotic disorder. Psychosom Med 2013;75 (January (1)):60-7.

[33] Coryell W, Zimmerman M, Pfohl B. Outcome at discharge and six months in major depression: the significance of psychotic features. J Nerv Ment Dis 1986;174(February (2)):92-6.

[34] Jäger M, Bottlender R, Strauss A, Möller HJ. Fifteen-year follow-up of Diagnostic and Statistical Manual of Mental Disorders, Fourth Edition depressive disorders: the prognostic significance of psychotic features. Compr Psychiatry 2005;46(September-October (5)):322-7.

[35] Coryell W, Endicott J, Keller M. The importance of psychotic features to major depression: course and outcome during a 2-year follow-up. Acta Psychiatr Scand 1987;75(Januray (1)):78-85.

[36] Buoli M, Caldiroli A, Altamura AC. Psychotic versus non-psychotic major depressive disorder: a comparative naturalistic study. Asian J Psychiatr 2013;6 (August (4)):333-7.

[37] Crebbin K, Mitford E, Paxton R, Turkington D. First-episode psychosis: an epidemiological survey comparing psychotic depression with schizophrenia. J Affect Disord 2008;105(January (1-3)):117-24.

[38] Park SC, Lee HY, Sakong JK, Jun TY, Lee MS, Kim JM, et al. Distinctive clinical correlates of psychotic major depression: the CRESCEND study. Psychiatry Investig 2014;11(July (3)):281-9.

[39] Rush AJ, Carmody TJ, Ibrahim HM, Trivedi MH, Biggs MM, Shores-Wilson K, et al. Comparison of self-report and clinician ratings on two inventories of depressive symptomatology. Psychiatr Serv 2006;57(June (6)):829-37.

[40] Upthegrove R, Marwaha S, Birchwood M. Depression and schizophrenia: cause, consequence, or trans-diagnostic issue? Schizophr Bull 2017;43(March $(2)): 240-4$.

[41] Musliner KL, Munk-Olsen T, Mors O, Ostergaard SD. Progression from unipolar depression to schizophrenia. Acta Psychiatr Scand 2017;135:42-50.

[42] Upthegrove R, Birchwood M, Ross K, Brunett K, McCollum R, Jones L. The evolution of depression and suicidality in first episode psychosis. Acta Psychiatr Scand 2010;122(September (3)):211-8.

[43] Gardsjord ES, Romm KL, Friis S, Barder HE, Evensen J, Haahr U. Subjective quality of life in first-episode psychosis: a ten year follow-up study. Schizophr Res 2016:172(April (1-3)):23-8.

[44] Challis S, Nielssen O, Harris A, Large M. Systematic meta-analysis of the risk factors for deliberate self-harm before and after treatment for first-episode psychosis. Acta Psychiatr Scand 2013:127(June (6)):442-54.

[45] Conley RR, Ascher-Svanum H, Zhu B, Faries DE, Kinon BJ. The burden of depressive symptoms in the long-term treatment of patients with schizophrenia. Schizophr Res 2007;90(February (1-3)):186-97.

[46] Salokangas RK, Saarinen S. Deinstitutionalization and schizophrenia in Finland: I. Discharged patients and their care. Schizophr Bull 1998;24(3):457-67.

[47] Rothschild AJ, Winer J, Flint AJ, Mulsant BH, Whyte EM, Heo M, et al. Study of pharmacotherapy of psychotic depression (STOP-PD) collaborative study group. missed diagnosis of psychotic depression at 4 academic medical centers. J Clin Psychiatry 2008;69(August (8)):1293-6.

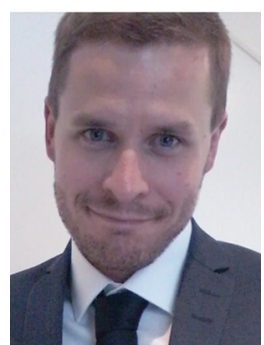

Miika Nietola, M.D., B.Soc.Sci, is a specialising physician in psychiatry at the University Hospital of Turku and a Ph. D. student in the University of Turku. 


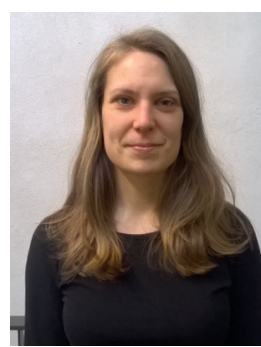

Anni Heiskala B.Sc. is in the process of finishing her Master's degree in Statistics at the University of Oulu. She has been working at the Center for Life Course Health Research, University of Oulu since 2016.

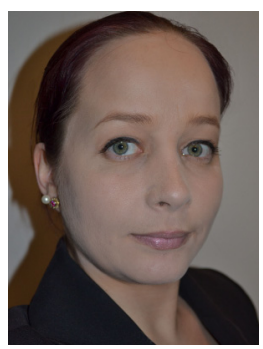

Ph.D Tanja Nordström works as a researcher and a statistician in University of Oulu. Previously, she has been studying adolescent ADHD and conduct disorders, and now focuses on gene-environment interactions for psychosis risk, structural equation modelling and various other statistical methods. She is also part of the data management group of Northern Finland Birth Cohorts.

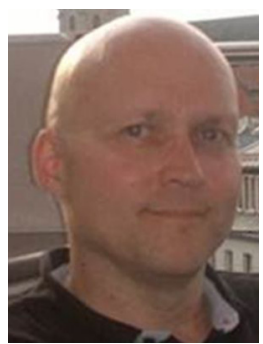

Prof Jouko Miettunen is a Professor of clinical epidemiology at the Center for Life Course Health Research, University of Oulu, Oulu, Finland. He is currently working also as Academy Research Fellow on risk factors for schizophrenia and as a vice-dean of the University of Oulu Graduate School. He has a M.Sc. degree in statistics from the University of Oulu, Finland, M.Phil. degree in epidemiology from the University of Cambridge, UK, and Ph.D. in psychiatry from the University of Oulu, Finland. He has over 240 publications, especially on schizophrenia, temperament and medical statistics.

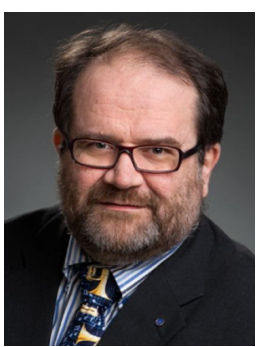

Jyrki Korkeila is a Professor of psychiatry at the University of Turku. He has over 120 peer-reviewed publications in medical journals. His research interests concern psychoses, epidemiology, stress, psychosomatics and psychiatric services. He is also former President of the Finnish Psychiatric Association and former Finnish WPA representative.

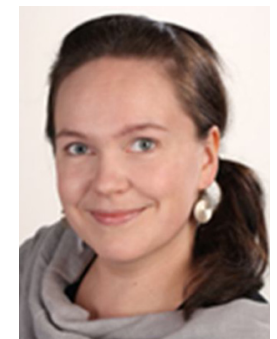

MD, PhD, Adjunct Professor Erika Jääskeläinen works as a researcher in University of Oulu and psychiatrist in Pihlajalinna Medical Center and Oulu University Hospital. She is especially interested on epidemiology, outcomes, cognition, and treatment in psychoses. 